\title{
Defensa extrajudicial del consumidor en la Argentina
}

\section{Extrajudicial Consumer Defense in Argentina}

\author{
Carlos Eduardo Tambussi* https://orcid.org/ 0000-0003-0444-7937
}

http://dx.doi.org/10.21503/lex.v18i26.2179

* Abogado, Universidad de Buenos Aires (1991). Ejerció libremente la profesión de abogado. Auditor Legal de la Administración de Parques Nacionales (2007-2010), Procurador Adjunto de Asuntos Patrimoniales y Fiscales del Gobierno de la Ciudad Autónoma de Buenos Aires (2010-2012). Secretario del Juzgado Nro. 18 Secretaría 35 del Fuero Contencioso Administrativo y Tributario de la CABA (2013-actualidad). Profesor Adjunto Regular: Universidad de Buenos Aires, Facultad de Derecho. Cátedra: Dr. Roberto Saba. Asignaturas: Derechos Humanos y Garantías y "Protección Constitucional de Consumidores y Usuarios" del Ciclo Profesional Orientado en la Facultad de Derecho (UBA). Docente en seminarios y cursos de posgrado sobre Derechos de Consumidores y Usuarios. Presidente de la Comisión de Derecho del Consumidor de la Asociación de Abogados de Buenos Aires. Argentina.

Correo electrónico: cetambu@uolsinectis.com.ar

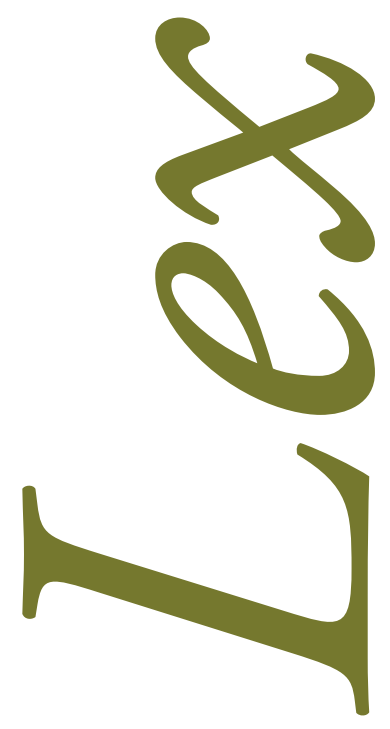




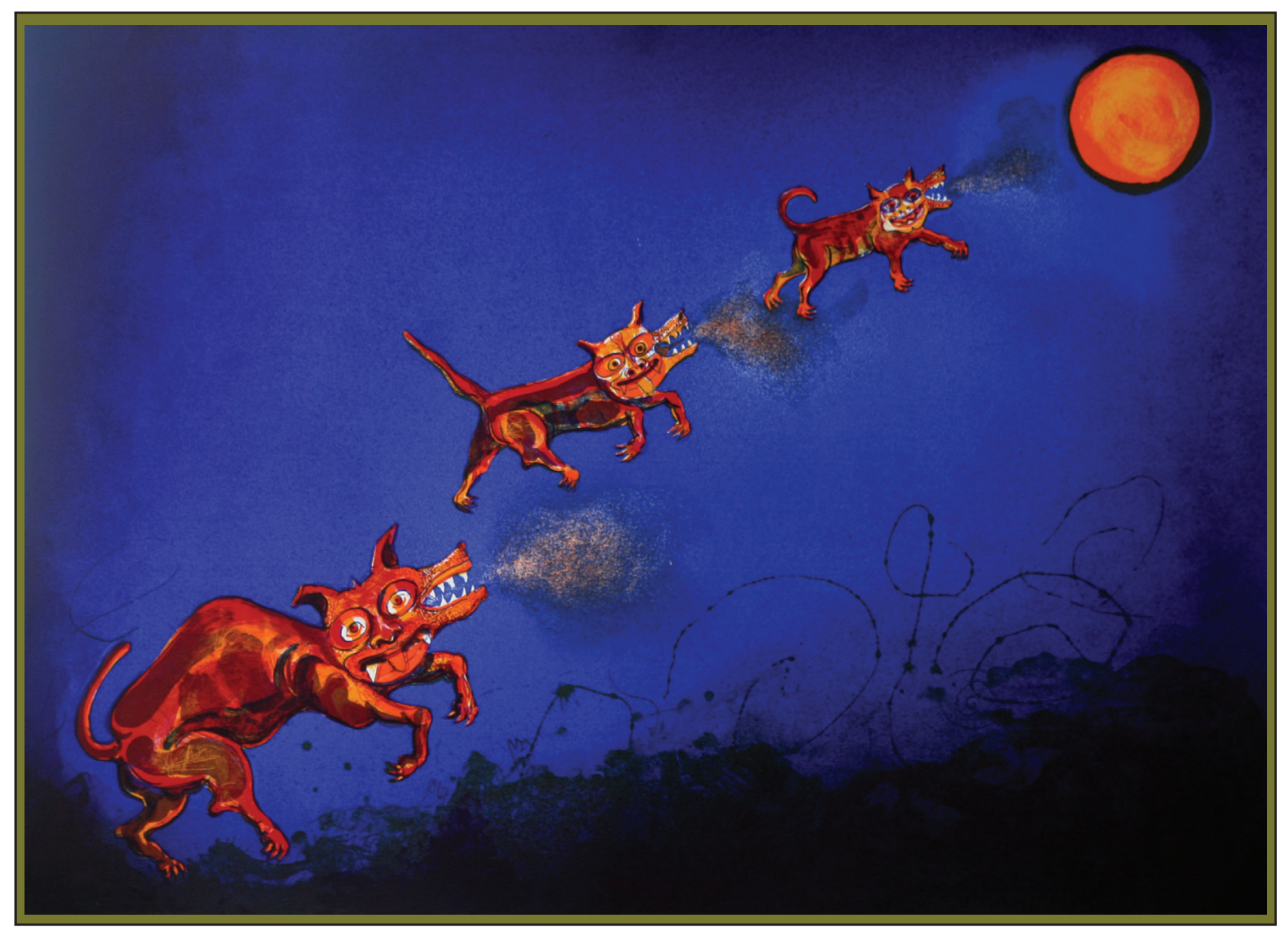

Perro enamorado de la Luna. Mixto, 1978. Artista plástico peruano, Alberto Quintanilla (Cusco 1934). 


\section{RESUMEN}

Existen en la República Argentina sistemas extrajudiciales de protección al consumidor dentro de la propia estructura del proveedor como posibilitados por el sector social o a través de organismos del estado, que es necesario poner en valor por su significado de funcionamiento y aplicación de la responsabilidad social empresaria, su impronta de propuesta de medios alternativos y sus posibilidades de arribo a conciliación o acuerdo ante las quejas planteadas. El ejercicio por parte de los consumidores de sus necesidades de reclamos por estos sistemas debe ser conocido y fomentado, ya que fortalece el concepto de ciudadanía y no impiden el reclamo judicial.

Palabras clave: consumidores y usuarios, sistemas extrajudiciales de reclamos, responsabilidad social empresaria, reclamo, defensor del cliente, denuncia administrativa, arbitraje de consumo, organizaciones sociales, Defensor del Pueblo, ciudadanía, participación.

\section{ABSTRACT}

In the Argentine Republic there are extrajudicial consumer protection systems within the provider's own structure as made possible by the social sector or through state agencies, which must be valued due to their meaning of operation and application of corporate social responsibility, its stamp of proposal of alternative means and its possibilities of reaching conciliation or agreement in the face of the complaints raised. The exercise by consumers of their claims needs through these systems should be known and encouraged, as it strengthens the concept of citizenship and does not prevent legal claims.

Key words: consumers and users, extrajudicial claims systems, corporate social responsibility, claims, customer advocate, administrative complaint, consumer arbitration, social organizations, Ombudsman, citizenship, participation. 


\section{INTRODUCCIÓN}

Las garantías son el fiel reflejo de la vigencia de los derechos, en el campo de la práctica. Ellas constituyen los mecanismos que un ordenamiento jurídico ha creado, pensando en defenderlos. Son la expresión de la realidad efectiva, de la existencia cierta de los derechos fundamentales, desde que posibilitan su defensa y su restablecimiento.

En el caso de los derechos del consumidor, su profundo sentido protectorio e igualador, nivelador de asimetrías y garante del acceso a bienes y servicios básicos para la vida de las personas, debe verificarse en las implementaciones concretas de su vigencia a través de políticas públicas que contribuyan a su protección dentro del universo de las posibilidades de reclamo.

El gran desafío de la actualidad y pese al gran desarrollo de estos derechos, por lo cotidiano de su problemática, es que las garantías sean tanto conocidas como asequibles a la comunidad jurídica y a los consumidores.

En el primer caso porque muchas veces los propios operadores jurídicos desconocen los sistemas de protección y en el segundo porque varios de los que existen están diseñados para que sea el propio consumidor, individual u organizadamente, quien los ponga en marcha. De ahí la necesidad de volver sobre la figura del consumidor - ciudadano, consciente de sus derechos y conocedor de los mismos, pero a la vez, guardián activo de su custodia.

Mas allá de la actividad de los organismos administrativos del estado de control y vigilancia del cumplimiento de las normas, los consumidores pueden ser una legión de fiscalizadores, supliendo las deficiencias o ausencias de control de las autoridades. Para ello, el sistema legislativo argentino propende a la educación al consumo como deber constitucional y contempla su financiamiento, pero esa retórica debe conjugarse - por sus efectos a largo plazo- con un andamiaje normativo que favorezca la constitución de organizaciones sociales de defensa del consumidor, y les dé una utilidad social efectiva y de campo. En esa línea veremos que la legitimación activa constitucionalmente reconocida en la carta magna argentina a las organizaciones no gubernamentales de consumidores es uno de los pilares para que sea posible una acción extendida tanto sobre la acción de los poderes públicos como de las conductas empresarias masivamente perjudiciales. 
Pero como veníamos diciendo, muchas veces el consumidor individual debe afrontar su problema localizado en el asunto que le atańe. El prejuicio general es el de creer que los temas de consumo refieren casi usualmente a menor cuantía y a rubro doméstico, cliché que un estudio apenas un poco más profundizado de lo que es el fenómeno de la relación de consumo protegida en su amplitud, desmiente inmediatamente. El sistema de responsabilidad por daños, la posibilidad de reclamos o planteos sin el requisito de haber contratado, los casos de exposición, las prácticas o situaciones jurídicas abusivas, la aplicación del daño punitivo o multa civil, y el significado social de muchas conductas de los proveedores que son decididas y valoradas en los conflictos de consumo, hacen de los mismos una universalidad diferente al mundo en que se los pretende reducir. Quizá en cantidad y por secuencia los asuntos de poca monta sean mayores, pero esto no convierte a la litigiosidad o pleito de consumo en el reduccionismo de casos de bagatela. Con solo repasar los múltiples servicios para destino final comprendidos en la vida diaria usual, y los bienes que suelen adquirirse o utilizarse, la problemática que generan los mismos respecto de los derechos fundamentales comprometidos (vida, salud, seguridad, integridad física, intereses económicos, libertad de contratar, acceso, calidad, y otros) nos aleja sustancialmente del encasillamiento menor.

En ese entendimiento, conocer y reseñar las formas de reclamar, contribuye a la plenitud de los derechos. Y éstas comienzan desde la etapa dentro de la misma empresa o proveedor infractor, y llegan hasta la imperativa decisión de un magistrado o hasta la fuerza expansiva de una decisión colectiva.

La presente es una reseña de las alternativas diseñadas en el caso argentino, cuyas líneas descriptivas anticipamos:

1. La cultura del consumo ciudadano, activo, consciente y defensor de sus derechos, se encuentra en formación, acicateada por los golpes que sistemáticamente los consumidores han sufrido a causa de políticas implementadas, sus consecuencias y situaciones económicas.

2. Se ha dado un desarrollo legislativo intenso desde la sanción de la ley de defensa del consumidor en 1993, tanto en el derecho nacional como local, y ha sido fuertemente impulsado con la consagración constitucional de 1994 y su inclusión en el Código Civil y Comercial vigente desde el 2015, que viene contribuyendo entre otras cosas a impregnar al derecho privado civil y comercial de los conceptos protectorios y solidaristas del régimen tuitivo consumidor, y de los valores constitucionales y convencionales de los derechos fundamentales o derechos humanos a los que el derecho de usuarios y consumidores pertenece. No obstante, persisten muchas deudas de implementación, como en caso de la ley de acciones colectivas, pendiente desde 1994 o la existencia de un fuero especial judicial para casos de consumo.

3. El movimiento de consumidores en la sociedad civil no es precisamente fuerte, no obstante, lo cual un estudio o reseńa honesta de su desempeño en el resultado de sentencias por acciones colectivas expresa un saldo positivo en la defensa en concreto de estos derechos, supliendo la inercia de los poderes públicos a la vez que enfrentando grandes intereses o negocios empresarios. 
4. Las políticas de las autoridades en los distintos niveles fluctúan en su gestión según el signo, dirigiendo muchas veces sus extinguidores a fuegos que podrían haberse evitado, y carecen de independencia de criterio respecto de la estructura a la que pertenecen.

\section{LA INSTANCIA EMPRESARIAL Y LA RESPONSABILIDAD SOCIAL DEL PRO- VEEDOR}

Las gestiones son aquellas tareas que el consumidor se ve obligado a realizar cuando en el marco de la relación de consumo sufre algún detrimento en sus derechos.

Existe entre consumidor y proveedor la diferencia entre el experto y el profano, que es "de carácter cognitivo, económico, social, operativo e informativo, al punto tal que algunos autores resaltan como elemento fundamental para la protección de los derechos de los usuarios la reducción de lo que denominan asimetría informativa. Nosotros consideramos que esa asimetría es esencialmente negocial, y que por ello no debe limitarse a lo informativo, ello debido a que también es cognitiva, económica, operativa, probatoria, jurídica y técnica”.

El derecho de usuarios y consumidores viene a igualar, a proteger, y no a terminar con la ganancia empresaria, a la que siempre va a considerar legítima mientras no se haga a costa del más débil. La aplicación de principios protectorios no va a importar que siempre el consumidor tenga razón, sino que la existencia de duda verdaderamente razonable será la que determine la aplicación del principio favorable en ese caso. El consumidor no está libre de efectuar denuncias infundadas y reclamos sin razón, y su protección necesaria no es la negación de esto.

Una visión empresaria integradora y social, debería concluir en que cumplir con la ley y honrar los derechos en juego en la Constitución y en la Ley 24.240, es la mejor vacuna para fidelizar su política de comercialización, prestigiar su marca y su servicio, en lugar de una gracia del poderoso que puede o no darse. Entenderemos esto como asumido el día en que esta disciplina sea internalizada en las planificaciones empresarias, en validez, vigencia y acatamiento de las normas, sin temor a nuevos institutos protectorios solo aplicables en caso de incumplimientos, violaciones a la buena fe o trato indigno, que como grupo económico siempre reclaman como motores de la economía y agentes del mercado que se consideran.

Veremos esto realizado en el momento en que puedan verse en conjunto las ventajas de consolidar la doctrina y el desarrollo de estos derechos, auspiciando a nivel empresa encuentros y jornadas donde se pongan en debate (cuestión que hoy solo se motoriza a través de universidades, ONG y entidades profesionales) y se formen los abogados empresariales o abreven los estudios jurídicos que las asesoran en las nociones protectorias y sociales de consumidores y usuarios, para que en la consulta brinden el contenido necesario desde el punto de vista jurídico para evitar a la empresa asesorada confrontar con la norma tuitiva. Podrían también, acompañar en la brega por consolidar la consideración como consumidores de las personas jurídicas, y en el afianzamiento de sistemas agiles y económicos para la solución 
de conflictos como por ejemplo el arbitraje de consumo, adhiriendo a la oferta pública, y anunciando en su publicidad la adhesión y la posibilidad de dirimir conflictos en forma sencilla, y sobre todo, dejar de lado el análisis económico de las consecuencias jurídicas de un comportamiento empresario, estando en juego derechos fundamentales de los consumidores.

Estimular las garantías, tiene también que ver con la atención debida en mecanismos internos de solución de los conflictos individuales, ya que cuando no está generalizado un efecto que pueda canalizar los casos en una acción colectiva, los problemas de consumo son la muestra de una verdadera dispersión de pequeños perjuicios, de pequeńas desgracias que el consumidor sufre aisladamente.

Más allá del reclamo en el establecimiento del proveedor, y los argumentos persuasivos que se puedan esgrimir en esas oportunidades, juegan también varios factores de oportunidad: desde el punto de vista del protagonista de nuestra historia, el consumidor, importan su firmeza de carácter, la conciencia de sus derechos y el manejo de su propia indignación.

Desde la posición del proveedor, existe — con previsión de cálculo— la certeza de las dificultades de los sistemas de quejas, el aprovechamiento de la falta de tiempo y de la necesidad del consumidor, todas cuestiones que hacen que podamos afirmar que se encuentra verdaderamente arraigado culturalmente el comportamiento desinteresado e indiferente, respecto de la atención y consideración de reclamos. Falla en general la política empresarial al respecto, y es débil o casi nula la capacitación de los empleados de atención al público o de "atención al cliente" (cuando los hay) a los efectos de aportar tranquilidad primero, y proponer una solución después. No obstante, además del reclamo manifestado o asentado en los libros de quejas que algunos ordenamientos mandan llevar en los establecimientos comerciales, es recomendable utilizar las vías propuestas por el proveedor de atención por chat, llamados a líneas gratuitas de atención al cliente u otras variantes despersonalizadas que han sabido implementar. A estos efectos, entendemos como tales a las prácticas de atención de reclamos que no importan la presencia física de reclamante y representante del reclamado. Como muy probable consecuencia de estudios de reducción de costos y optimización de beneficios, pero también de aventar reclamos y despejar temperamentos desesperados e inquietos de los consumidores, muchas empresas de distinto nivel han implementado que su modalidad de atención al cliente para las quejas sea por vía impersonal, con la amabilidad de su gratuidad.

Interactuamos con varios mecanismos del proveedor, y vemos que al usarlos somos compartimentados entre los distintos sectores con los que se nos comunica, ante los cuales debemos identificarnos y repetir incesantemente hasta nuestro número de cliente que el proveedor mismo debe tener y el motivo de nuestro llamado. Todo esto si no incluimos en la reseña los sistemas de reclamos por chat robótico, la atención por mensajes grabados con un lenguaje musical e inentendible, y/o directamente la existencia de empresas sin ningún centro físico de atención al público y que ni siquiera identifican la localización de su sede en su página web, cerrando el círculo del camino a la total despersonalización y a perseguir el desaliento al reclamo, a conducir a la resignación. 
Sin duda estas mini tragedias están calculadas en su significación económica, desde la perspectiva del que las causa, y también está prevista la inacción del afectado, dando un resultante que arroja fácilmente la conclusión para el mal proveedor acerca de que es más conveniente continuar con la práctica, (incluso afrontando los costos de las eventuales reclamaciones que avancen), en lugar de adaptarla o suprimirla. Un simple ejercicio de "análisis económico del derecho" que realiza el empresario ${ }^{1}$. No pueden comprenderse las perdurabilidades de ciertas prácticas sin partir de esta premisa. Los partidarios del análisis económico del derecho entienden que la redistribución de la renta debe ser un objetivo del sistema fiscal, es decir, del sector público del derecho. En esa inteligencia, el derecho privado debe, por el contrario, buscar la solución más eficiente, que es aquella que genere el aumento de la suma total de beneficios

El derecho del consumidor arraiga en el estudio de cuestiones económicas, y las visiones desde esta disciplina son absolutamente necesarias en el abordaje interdisciplinario que hace falta en la materia. Pero fiel a su espíritu nivelador, los principios de este derecho son refractarios a subordinar al derecho a las leyes de la economía, en el sentido que este sólo debe contemplarlas y facilitarlas. El costo-beneficio como parámetro del análisis no puede ser medido únicamente en términos económicos, si ello importa sacrificio de derechos y valores que pueden ser -al menos- axiológicamente superiores al beneficio material. Por ello los autores advierten que no debe proponerse el "extremismo de la anulación del sistema normativo o su reducción a simple escudero de pretensiones económicas sectoriales, con la consiguiente sepultura de las metas de interés general. Una desviación así importaría una auténtica malversación normativa”"2.

Sin embargo, el aprovechamiento del sistema de reclamos aun impersonal es direccionado a la búsqueda de beneficios. Las opciones de reclamos no existen en el menú de números u opciones que se nos ofrecen, siendo necesario escoger alguna que implique contratación de servicios o interés comercial del proveedor para ser atendidos. A su vez, las esperas telefónicas no solamente insumen prolongado tiempo, sino que son aprovechadas para hacer publicidad (muchas veces adosadas al saludo al atender el sistema) y tantas otras estrategias: muchas veces, al concluir, debemos aportarle gratuitamente un servicio nuestro al proveedor, contestando una encuesta cuando nos hemos contactado para una queja.

Vaya a saber qué se enseña al respecto en las facultades de carreras empresariales, que estrategia de marketing, para nada emparentada con la fidelización o contención del cliente entronca con estas prácticas. Cuando la cuestionamos, se nos replica muchas veces que atención personalizada no implica necesariamente presencia humana, sino atención directa y que a través de los servicios telefónicos, que los call center suelen solucionar con mucha más rapidez y sin que el consumidor se acerque al estable-

1. Jorge Alejandro Amaya, Mecanismos Constitucionales de Protección al Consumidor (Buenos Aires, Ed. La Ley, 2004), 61.

2. Jorge Reynaldo Vanossi, La aplicación constitucional del Análisis Económico del Derecho: nada menos y nada más que un enfoque (Anales de la Academia Nacional de Ciencias Morales y Políticas. Tomo XXXV, Buenos Aires, 2008), 159. 
cimiento, los problemas que puedan presentarse.

Pero lo cierto es que los seres humanos quedan reservados para atender las actividades comerciales y generadoras de beneficios, quedando los teléfonos para las cuestiones inocuas en rédito, siempre desde el punto de vista empresario. Y he aquí el error, que reside en no comprender que una atención humana y contenedora, arroja un resultado no palpable en números en forma directa, sino en valores que generan y mantienen clientela, que son la razón de ser de la actividad empresarial. La cultura vertiginosa y apurada de los servicios, incluye la deshumanización de los reclamos. Con esa vara se miden desde algunas lógicas mercantiles los sistemas de atención al cliente, aprovechándose de la inercia de la costumbre, que hace que se abandonen los reclamos por cansancio, fortaleciéndose de esa manera la cultura (o subcultura) del mal servicio.

De cualquier manera, insistimos siempre que a nuestro criterio, usar los canales que el mismo proveedor ofrece, en un primer intento de plantear nuestra posición como consumidores y buscar una solución, superando el ejercicio de voluntad y persistencia que supone, es recomendable para ejercitación de la conducta del reclamo, a la vez que evidencia la conducta del proveedor respecto del trato digno que puede ponderarse judicialmente, y puede ser vista como una forma de desarrollar ese aspecto del derecho del consumo que es la responsabilidad social empresaria (comprensiva de las llamadas "buenas prácticas").

Cuando resulta vana la empresa o insatisfactoria, el estado implementa y ofrece el sistema de reclamos administrativos, el arbitraje de consumo y el sistema judicial donde la historia será otra. Pero no incumbe solamente las autoridades el marco contencioso o infraccional, puesto que también puede contribuir a fortalecer la alternativa que el proveedor ofrezca una instancia voluntaria para la atención de los conflictos dentro de su propia estructura.

\section{LA FIGURA DEL DEFENSOR DEL CLIENTE}

Con la regulación del Defensor del Cliente (Res. 394/2018 de la Secretaria de Comercio de la Nación) se puso en valor de un mecanismo de auto regulación, una posibilidad más, que el proveedor decidirá si la ofrece y puesta en marcha, el consumidor considerará si le satisface o la considera apta. Las empresas adheridas al momento en que este trabajo se escribe son solo seis y pueden consultarse en https://www.argentina.gob.ar/defensadelconsumidor/defensor-del-cliente.

Se trata de un funcionario de la estructura del proveedor. Las empresas que lo adopten tienen la obligación de informar a los consumidores la existencia de esta modalidad de reclamo, sus procedimientos y condiciones, a través de las oficinas de atención al público (aclaramos nosotros, cuando existan) y los sitios web, bajo la pauta de máxima visibilidad.

A su vez el estado toma a su cargo la difusión de las empresas que hayan implementado el sistema, determinándose además un monitoreo trimestral de gestión respecto a la cantidad de asuntos tratados, monto, resultado, y demás aspectos. 
La normativa establece que la empresa debe someter a homologación el reglamento de tramitación de reclamos ante el Defensor, y las condiciones que tiene que cumplir la persona que sea propuesta. La instancia de reclamo ante el Defensor del Cliente es esencialmente voluntaria y gratuita y no implica renuncia alguna a los demás sistemas. Conforme el reglamento homologado, el Defensor deberá emitir resoluciones que de ser aceptadas por el consumidor o usuario, tendrán carácter vinculante y de cumplimiento imperativo para el proveedor.

\section{LA PRESENTACION DE UNA DENUNCIA ANTE LA AUTORIDAD DE APLICACIÓN}

A través del procedimiento administrativo vigente en cada provincia y en la Ciudad Autónoma de Buenos Aires, el consumidor puede denunciar el incumplimiento del proveedor a su respecto, acceder a instancias conciliatorias donde intentar arribar a una solución que de no lograrse en esa oportunidad provoca que el procedimiento continúe sin su intervención, quedando en manos de la autoridad de aplicación resolver sobre la infracción legal denunciada, que puede incluir algunos aspectos reparatorios del daño que se hubiese sufrido, si se pide daño directo, como ya veremos.

De aplicarse finalmente una sanción, la misma puede ser cuestionada judicialmente por el proveedor. En caso de quedar firme o ejecutoriada, en caso de ser patrimonial es aplicada al destino previsto en la normativa, y salvo en el caso de la fijación de una reparación por daño directo, la continuidad de la actuación administrativa no otorga una solución completa al consumidor afectado. Por eso muchas veces nos referimos a la denuncia administrativa como un acto cívico, ya que las chances del consumidor de obtener una solución efectiva a su problema dependen de la voluntad conciliatoria de ambas partes, o de la suerte de su reclamo de dańo directo.

La actuación administrativa puede ser previa, simultánea o posterior a la acción judicial, y esta última no importa el desistimiento de la primera, atento su distinta naturaleza. ${ }^{3}$

En caso de producirse transacción en sede administrativa, no se podrá accionar judicialmente sobre cuestiones acordadas en esa instancia, o en el caso que se haya renunciado en forma expresa a la acción judicial o se manifestare que nada más se tiene que reclamar.

La denuncia administrativa puede servir además para preconstituir prueba, verificar la respuesta del proveedor a los reclamos, su voluntad conciliatoria, dilatoria o directamente remisa, que como parte del trato al consumidor ha sido tenida en cuenta en sede judicial para graduar el daño punitivo.

Respecto a la eventual decisión de la autoridad de aplicación, las opiniones están divididas entre quienes entienden que lo allí decidido no es vinculante para el magistrado, sin perjuicio del valor como

3. Maximiliano Rafael Calderón, Manuel Cornet, Guillermo Tinti, José Fernándando Márquez. "Proceso judicial de Consumo. Análisis de los arts. 52 y 53 de La Ley 24.240”. En La Ley Córdoba (junio, 2009): 459. 
antecedente de lo resuelto y los que piensan que la resolución administrativa es oponible al consumidor actor judicial, en el caso que haya tenido intervención en el procedimiento administrativo. ${ }^{4}$

El procedimiento de defensa del consumidor ante la autoridad administrativa tiende a la verificación y sanción de infracciones, es una instancia donde la autoridad de aplicación de la ley de defensa del consumidor investiga, interpreta y aplica la norma en caso de verificarse una infracción a la misma, ejerciendo en su caso la potestad sancionatoria. La autoridad también puede actuar por sí, mediante su actividad inspectiva de verificación de infracciones.

Como hemos expresado, la oportunidad conciliatoria importa una posibilidad para el consumidor de obtener alguna satisfacción a su reclamo (nunca integral en sentido estricto), pero -en principiopensada para ser más rápida que la de la demanda judicial, con las particularidades y limitaciones que señalaremos.

La presentación de este tipo de reclamos es esencialmente gratuita, no requiere patrocinio letrado (no es obligatorio pero siempre debemos recordar que no está prohibido), no se opone a la posibilidad del reclamo judicial, y-como veremos- puede significar un ámbito donde el consumidor es escuchado, recibido su planteo y asistido en sus derechos, ya que la autoridad de aplicación tiene el deber legal de defenderlo.

El reclamo administrativo ha crecido en su utilización por parte del consumidor, que empieza a ver ese escenario como una posibilidad válida de obtener algún tipo de solución a sus problemas. A su vez, siendo esto sólo posible en la instancia conciliatoria, esa puesta en valor y nueva visión respecto de la conciliación en sede administrativa se da porque también los proveedores han ido paulatinamente comenzando a entender la necesidad de acudir a esas audiencias con propuestas que conduzcan a un acuerdo, cierren el expediente y de esa manera evitar eventuales sanciones y cuiden el nombre o prestigio de su marca o comercio.

Dado nuestro sistema federal, coexisten una autoridad de aplicación nacional y autoridades locales 5 que ejercen el control, vigilancia y juzgamiento del cumplimiento de la ley, de modo que debemos conocer en cada provincia cuál es la agencia competente y sus normas de procedimiento administrativo.

Todo ello sin perjuicio de las competencias concurrentes de la autoridad nacional de aplicación (en términos del art. 45 de la ley 24240). El elemento que toma en cuenta la ley para atribuir la competencia de la autoridad de aplicación es la jurisdicción donde haya ocurrido la presunta infracción. En la práctica y para evitar un doble juzgamiento sobre un mismo hecho, intervendrá la autoridad de aplicación local cuando la presunta infracción se produzca en el ámbito de su jurisdicción e intervendrá

4. Juan F. Farina, Defensa del Consumidor y del Usuario (Astrea, Buenos Aires, 2000), 484-85.

5. https://www.argentina.gob.ar/produccion/consumidor/oficinas-provinciales, acceso del 1 de septiembre de 2020. 
la autoridad nacional cuando se den conflictos interjurisdiccionales ${ }^{6}$ y en aquellos casos en que por razón de la materia estén reservados a la jurisdicción federal. La pauta es que el poder de regular y aplicar el régimen sancionador "es básicamente, poder no delegado por las provincias en el estado federal, y consecuentemente, conservado por éstas"7.

En el procedimiento administrativo rigen los principios de: legalidad, informalismo, verdad material objetiva y la garantía del debido proceso legal. Los presuntos infractores gozan del derecho a ser oídos, a ofrecer y producir pruebas y a que las decisiones que la autoridad adopte sean fundadas. El asesoramiento de la autoridad de aplicación en la presentación de denuncias, y la flexibilización de formalidades como aplicación del principio pro actione es fundamental para el acceso a este procedimiento, donde debe ayudarse al consumidor a subsanar cualquier formalidad o dificultad que la presentación del caso pueda causarle. Existe un deber de la Administración de instruirlo de forma tal de llegar a la verdad material de los hechos y, a su vez, contemplar y considerar los argumentos y las pruebas pertinentes ofrecidas por quien está siendo investigado. El acto administrativo, como producto del ejercicio de la función previa, tiene necesariamente que ser la derivación del respeto de las garantías del administrado y una consecuencia razonada y razonable de las circunstancias esenciales (fácticas y jurídicas) allegadas y producidas en el expediente.

La denuncia debe identificar al presentante y en su caso acreditar la personería invocada, constituir domicilio, individualizar a él o los denunciados. Contendrá un relato de los hechos y se acompańará la documentación con la que se cuente o la indicación del lugar donde se encuentra, aun en el caso que esté en manos del proveedor. En lo posible es prudente incluir la pretensión del consumidor, y como ya veremos el reclamo por dańo directo, en su caso.

\section{LA LLAMADA “VENTANILLA FEDERAL” y LA ESPECIAL CONSIDERACION DE LA VULNERABILIDAD AGRAVADA}

La Disposición 663/2019 de la Dirección Nacional de Defensa del Consumidor institucionalizó la "Ventanilla Federal Única de Reclamos de Defensa del Consumidor" que funcionaba desde 2017, con el propósito de facilitar la presentación de denuncias en una plataforma electrónica, donde la autoridad nacional distribuye y asigna a las autoridades locales los reclamos que por ésta ingresa, a los fines de su resolución. El sistema permite incluso agregar documentación, y es un derivador de casos que genera el comienzo del proceso administrativo según las normas locales.

Puede accederse a ella en https://www.argentina.gob.ar/iniciar-un-reclamo-ante-

defensa-de-las-y-los-consumidores, donde se incluyen formularios de denuncia.

Por su parte, la reciente Resolución SCI 139/2020 de la autoridad de aplicación nacional, contempla la situación de los consumidores con vulnerabilidad agravada o hipervulnerables, entendiendo por

6. Horacio Luis Bersten, Derecho Procesal del consumidor (La Ley, Buenos Aires, 2004), 24.

7. Carlos Balbín, Tratado de Derecho Administrativo, Tomo 2 (Buenos Aires. La Ley 2015), 484. 
tales "a aquellos consumidores que sean personas humanas y que se encuentren en otras situaciones de vulnerabilidad en razón de su edad, género, estado físico o mental, o por circunstancias sociales, económicas, étnicas y/o culturales, que provoquen especiales dificultades para ejercer con plenitud sus derechos como consumidores. Asimismo, podrán ser considerados consumidores hipervulnerables las personas jurídicas sin fines de lucro que orienten sus objetos sociales a los colectivos descriptos”. En esa línea dispone la realización de acciones para eliminar los obstáculos que puedan tener estos grupos en el acceso al sistema de reclamos, entre otras medidas.

\section{ACCESIBILIDAD Y TRAMITE DEL PROCEDIMIENTO ADMINISTRATIVO}

Algunos ordenamientos procesales determinan el otorgamiento de turnos vía web o por teléfono, prevén la constitución de domicilios electrónicos para acelerar las notificaciones, pero su contemplación es dispar y lenta en admitirse. En otros casos, la descentralización no es completa y solo se encuentra en cercanía la recepción de la denuncia hasta la realización de la etapa conciliatoria, quedando más lejana la tramitación de los sumarios. La descentralización contribuye como incentivo para los reclamos atento la inmediatez que el consumidor puede aprovechar entre la ventanilla de ingreso del trámite y su domicilio o lugar de peso habitual.

Suele contemplarse la presentación del denunciante por sí, por representante o mediante la intermediación de una asociación de consumidores debidamente registrada. La ley de defensa del consumidor, en la tesitura de la amplitud necesaria del acceso al sistema de reclamos y la celeridad del proceso mediante una verificación rápida de la personería, establece que con una simple acta poder se acredita la representación para estar en juicio o para realizar la denuncia administrativa ${ }^{8}$. Conforme el art. 53 de la ley nacional 24240 “...quienes ejerzan las acciones previstas en esta ley representando un derecho o interés individual, podrán acreditar mandato mediante simple acta poder en los términos que establezca la reglamentación".

En lo pertinente a la exigencia de la documentación que acredite la relación de consumo, cabe señalar que no siempre debe vincularse a la existencia de un contrato, conforme al amplio criterio constitucional y legal de relación de consumo, que comprende aspectos previos, concomitantes y posteriores al contrato, como también la mera utilización del bien o servicio.

También según el caso, será necesario acreditar la pertenencia al grupo familiar o social del consumidor o aportar los elementos que acrediten la utilización de un bien o servicio cuya adquisición realizó otro, de conformidad con el segundo párrafo del artículo 1 de la LDC, quien “...sin ser parte de una relación de consumo, como consecuencia o en ocasión de ella adquiere o utiliza bienes o servicios como destinatario final, en beneficio propio o de su grupo familiar o social." Se encuadran en este supuesto, los sujetos que reciben la cosa como regalo o presente de estilo y los sucesores universales y singulares

8. Véase Carlos Tambussi, "Juicios y Procesos de Consumidores y Usuarios”, Colección Procesos Constitucionales $N^{\circ} 7$. Director Pablo Luis Manili, Ed. Hammurabi Bs As, (2014): 309 y sgtes. 
del consumidor.

En su caso rigen los principios de las cargas dinámicas de la prueba ${ }^{9}$. La aplicación de esta teoría a los reclamos de consumo, incorporada para las acciones judiciales por la ley 26361 que en el año 2008 reformó la ley de defensa del consumidor 24240, impone la aportación de la prueba a la parte que se encuentra en mejores condiciones para producirla, pues ambos litigantes están obligados a colaborar en el esclarecimiento de la verdad jurídica objetiva, que es el objeto de todo juicio, en el marco de la pretensión deducida. Nada obsta a su aplicación al reclamo administrativo.

En cuanto a la pretensión, debe tenerse en cuenta que el inicio del procedimiento administrativo por denuncia no es una demanda judicial y bien pueden determinarse los términos de la pretensión a posteriori, cuando el consumidor asesorado sepa qué es lo que puede pretender. La denuncia debe ser lo más autosuficiente posible, a los fines de comunicar enteramente el contenido y el origen del reclamo al proveedor, y sobre todo facilitar la búsqueda de los ejes para la etapa conciliatoria o en su caso, determinar los hechos objeto de prueba y el eventual fundamento de la sanción que se aplique, sin perjuicio del reclamo por daño directo.

Es necesario individualizar a los proveedores denunciados, aspecto que puede resultar necesario en caso de pretenderse la responsabilidad solidaria o concurrente en materia de consumo que establece la legislación argentina, que permite incluir en el procedimiento a los responsables en términos de la ley en su calidad de integrantes de la llamada "cadena de valor" o por criterios atribuidos por el legislador (responsabilidad por garantía, servicio técnico y repuestos, por ejemplo). La debida identificación sirve además para posibilitar su citación a la audiencia conciliatoria.

Esta tarea es a veces difícil cuando los proveedores ocultan su identidad jurídica, y la autoridad de aplicación puede colaborar en esa dificultosa identificación y puede pedir al consumidor en presencia de esos obstáculos la mayor cantidad de datos que permitan esa tarea o el aporte del nombre de fantasía, vinculable con su propietario mediante la consulta a los registros marcarios. Igual criterio en caso de que solo se cuente con el "link" o página web, donde puede identificarse registralmente al dueño del sitio o tomarse los datos del proveedor que de ella (eventualmente) surjan.

Como dijimos, el primer paso suele ser la citación a una audiencia conciliatoria, de la que los denunciados se enteran porque reciben una notificación con el contenido de la denuncia y día y hora de la audiencia. De modo que los proveedores acuden a la audiencia en pleno conocimiento del contenido del reclamo y de la entidad de su ética comercial dependerá no argumentar en la primera audiencia desconocer el planteo y no tener instrucciones.

La promoción de la conciliación como deber de la autoridad implica su puesta en valor como parte

9. Véase Carlos Tambussi, "La teoría de las cargas dinámicas de la prueba en los procesos de consumo" Publicado en Erreius "Revista Temas de derecho comercial, empresarial y del consumidor", Año 1, diciembre de (2015): 43-49. 
del procedimiento ineludible y suele comprender multas al proveedor en caso de incomparecencia. Es de fundamental trascendencia para el consumidor que ha optado por esta vía de reclamo. En ella, el o los proveedores citados pueden hacer gala de un sostenimiento cabal de su sentido de responsabilidad social empresaria y ofrecer al reclamante una solución -incluso hasta reparatoria- al menoscabo sufrido. Pero está la otra parte de la historia. El proveedor sabe y cuenta con el poco tiempo y la escasa dedicación del consumidor a la persistencia. Los escasos consumidores más concientizados saben que la eventual sanción tarda en llegar, de arribar es por supuesto apelable y muchas veces no se compara con el menoscabo o daño sufrido, y que una eventual sentencia judicial si deciden acometer la contienda también es lerda en fructificar. Por esa razón muchos proveedores tienen como política no asistir a las conciliaciones o hacerlo para eludir la multa por incomparecencia, pero no formular propuesta alguna, temperamento al que obviamente no están obligados. Nobleza obliga también hay otros que han asumido la postura contraria y de esa manera fidelizan al consumidor y colaboran con el sistema. La experiencia indica que es en ocasiones la marca la que busca defender su prestigio en el mercado, y cuando es codenunciada ofrece alguna alternativa aceptable para el consumidor, muchas veces distinguible de la indiferencia de ciertos comerciantes que se desprenden de toda consideración al respecto.

Las propuestas laterales de solución muchas veces tienen que ver con el no muy esforzado ingenio conciliatorio que puede consistir por ejemplo en el ofrecimiento de un producto de generación posterior o con valor agregado tecnológico en reemplazo del problemático o sin funcionamiento. Por su parte, los consumidores suelen rechazar el ofrecimiento de órdenes de compra por el monto pagado en el mismo establecimiento o la sustitución del producto, por significar una forma más abierta y expuesta de renovar la confianza en quien y con quien ya han tenido un inconveniente grave.

En la/s audiencia/s conciliatorias es la autoridad de aplicación encarnada en el audiencista, quien tiene que orientar y guiar al reclamante y a la vez encarnar la vigilancia del orden público y el régimen tuitivo consumidor en esos actos, velando porque no solamente el eventual acuerdo satisfaga al denunciante en lo personal, sino para que no implique desmedro a estos valores. De ahí que sea fundamental la capacitación constante y versación en materia de estos derechos para estos funcionarios, que debe basarse tanto en conocimiento normativo como en técnicas de solución negociada de controversias. A cargo de ellos está todo el desarrollo de la instancia conciliatoria, y son a la vez los que remiten las actuaciones al nivel de decisión para considerar la homologación del eventual acuerdo, o los que otorgan la constancia de cierre de esta etapa previa sin acuerdo, pasando los autos a instrucción sumarial. Existe también la posibilidad que las partes acuerden fuera del procedimiento, haciéndolo saber a la autoridad de aplicación mediante la presentación de los términos convenidos, que también se somete a control y homologación.

Cualquier acuerdo al que se arribe debe constar en el expediente en cuanto a sus términos, condiciones, modalidades, plazos, y demás cuestiones sustanciales y operativas.

El acuerdo conciliatorio homologado produce el cese de la potestad sancionatoria de la autoridad 
de aplicación, sujeto a su cumplimiento. Por esa razón, de no observarse lo pactado, el proveedor incurre en violación a la ley. La aplicación de la sanción por incumplimiento de acuerdo homologado no es automática, sino que se requiere que el consumidor efectúe una presentación ante la autoridad de aplicación, denunciando el incumplimiento del acuerdo conciliatorio homologado. El incumplimiento del acuerdo puede ser total o parcial para ser pasible de sanción. Para el supuesto de tener que hacer efectiva la obligación de dar o de hacer que el proveedor comprometió en el acuerdo e incumplió, el cumplimiento puede compelerse mediante el sistema de ejecución de sentencias de los procedimientos judiciales de cada jurisdicción.

Concluida sin acuerdo la etapa conciliatoria, los presupuestos que dan lugar al dictado del acto de imputación son los relacionados con la apreciación prima facie de la existencia de los hechos denunciados con las pruebas reunidas por el consumidor, y/o las verificaciones técnicas efectuadas, como emergentes de una posible infracción a la legislación vigente. El acto de imputación marca el comienzo de la instrucción del sumario infraccional y debe ser notificado a el/los proveedores, indicando en términos claros y concretos la normativa presuntamente infringida, la descripción sintética de la forma en que fue constatada y el derecho a presentarse a la instrucción por sí o por apoderado. Si la imputación se hubiese hecho en el acta de constatación de oficio, puede ampliarse o rectificarse. Importa el emplazamiento al proveedor a presentar descargo y ofrecer prueba. La ausencia de dicho requisito, esencial del procedimiento, afecta el debido proceso adjetivo con repercusión en el derecho de defensa del sancionado, lo cual acarrea la nulidad del acto. Si la autoridad de aplicación no imputa específicamente una conducta a quien fue denunciado por infringir la referida norma, mal puede este último ejercer adecuadamente su derecho a ser oído, ofrecer y producir prueba, y obtener una decisión fundada sobre su situación.

Las pruebas deben versar sobre hechos controvertidos, conforme el principio general y deben ser conducentes Producida la prueba, las normas de procedimiento suelen fijar plazos algo extensos para que la autoridad de aplicación dicte resolución, previo dictamen jurídico.

El acto administrativo debe expresar cuál es la conexión entre los fundamentos utilizados para imponer la sanción y los hechos probados en el expediente, examinando los planteos expuestos en el descargo. Debe contarse con elementos probatorios para castigar. En esta materia la carga de la prueba corresponde a la Administración, y su ausencia debe traducirse en la absolución. También debe decidir sobre daño directo, en caso de haber sido solicitado.

Las sanciones se pueden aplicar independiente o conjuntamente, según las circunstancias del caso. Conforme artículo 47 ley 24240 son las siguientes:

. Apercibimiento (única que no se aplica en forma conjunta)

. Multa: Las multas que la autoridad de aplicación está autorizada a imponer en el marco de las infracciones a la ley 24240 no tienen por objeto resarcir al denunciante por los perjuicios sufridos, sino que se trata de medidas disuasivas tendientes a prevenir futuros comportamientos lesivos de los 
derechos de los consumidores. Para la aplicación de la multa administrativa, no es necesario demostrar que el infractor ha obrado con dolo, esto es, con una deliberada intención de incumplir o la voluntad de realizar el supuesto de hecho típico, sino que es suficiente con la acreditación de un obrar culposo o negligente.

. Decomiso de las mercaderías y productos objeto de la infracción.

- Clausura del establecimiento o suspensión del servicio afectado por un plazo de hasta 30 días.

. Perdida de concesiones, privilegios, regímenes impositivos o crediticios especiales de que gozare.

La sanción pecuniaria se gradúa conforme los siguientes criterios: El perjuicio resultante de la infracción para el consumidor o usuario, la posición en el mercado del infractor, la cuantía del beneficio obtenido, el grado de intencionalidad, la gravedad de los riesgos, o de los perjuicios sociales derivados de la infracción y su generalización, la reincidencia y las "demás circunstancias relevantes del hecho".

La resolución sancionatoria debe publicarse en el Boletín Oficial a costa del proveedor, también en un diario de circulación general designado por sorteo, e inscribirse en el Registro de Infractores, entre otros fines, para el cómputo de la reincidencia en caso de que corresponda.

Los ordenamientos regulan la revisión judicial del acto administrativo sancionatorio y en su caso de la determinación de daño directo por la autoridad de aplicación, en general mediante recurso directo en segunda instancia, con distintas competencias en razón de la materia en cada jurisdicción.

El acto sancionatorio firme, es ejecutable por el Estado mediante el juicio ejecutivo o de apremio o de ejecución fiscal.

El ordenamiento nacional prevé también el dictado de medidas preventivas administrativas, en caso de que sea necesario asegurar los derechos protegidos o prever que se produzcan dańos o se agraven los causados.

\section{LA POSIBILIDAD DE REPARACION EN SEDE ADMINISTRATIVA}

Toda persona que haya sufrido perjuicio o menoscabo a su derecho como usuario o consumidor susceptible de apreciación pecuniaria y sufrido en forma inmediata sobre sus bienes como consecuencia de la acción u omisión del proveedor de bienes o servicios ofrecidos puede además reclamar una indemnización por dańo directo. Esta figura contempla la posibilidad que los consumidores reclamen, en instancia administrativa, un resarcimiento económico por el perjuicio sufrido en la relación de consumo, y que la autoridad de aplicación determine su procedencia y obligue en su caso a reparar al usuario o consumidor por los daños resultantes de la conducta del proveedor o del prestador en la 
relación de consumo.

El instituto está regulado en el art. 40 bis de la ley 24240, que establece garantías institucionales que debe cumplir el organismo competente para su aplicación, lo que tiene un gran impacto en las estructuras y procedimientos administrativos locales. No contempla un tope indemnizatorio como lo hacía en su redacción anterior, dejando por ello, a criterio de cada jurisdicción la determinación de estos aspectos. Esas características institucionales establecidas por la legislación consignan que la Autoridad de Aplicación del daño directo debe reunir los requisitos de haber sido creado por una norma que le conceda facultades para resolver conflictos entre particulares, que tienen que estar dotada de especialización técnica, independencia e imparcialidad indubitadas, y sus decisiones deben estar sujetas a un control judicial amplio y suficiente. Estas exigencias responden a la adecuación a las pautas jurisprudenciales de la CSJ sobre tribunales administrativos de los fallos "Ángel Estrada” y "Fernández Arias"10 que habilitarían la excepcionalidad de que los órganos administrativos puedan ejercer facultades jurisdiccionales, las que en principio se encuentran vedadas por los arts. 18 y 109 de la $\mathrm{CN}$.

A la hora de la realidad, salvo en la Ciudad Autónoma de Buenos Aires ${ }^{11}$ y alguna otra excepción, no es de aplicación frecuente, por los siguientes motivos: a) las exigencias legislativas respecto de las características de la autoridad de aplicación, que no se cumplen prima facie respecto de la mayoría de las agencias de consumo, b) su desconocimiento por la comunidad jurídica y por los consumidores.

\section{EL ARBITRAJE DE CONSUMO}

A cinco años del dictado de la ley de defensa del consumidor 24240, y en cumplimiento de su artículo 59, por Decreto 276 del 28 de marzo de 1998 se puso en marcha Sistema Nacional de Arbitraje de Consumo, poniendo en cabeza de la autoridad de aplicación su organización y funcionamiento, cuya última formulación fue realizada por la Resolución 65/2018.

Dice el art. 59 de la ley de defensa del consumidor:

“Artículo 59. - Tribunales Arbitrales. La autoridad de aplicación propiciará la organización de tribunales arbitrales que actuarán como amigables componedores o árbitros de derecho común, según el caso, para resolver las controversias que se susciten con motivo de lo previsto en esta ley. Podrá invitar para que integren estos tribunales arbitrales, en las condiciones que establezca la reglamentación, a las personas que teniendo en cuenta las competencias propongan las asociaciones de consumidores o usuarios y las cámaras empresarias.

10. CSJN, 05/04/2005 “Ángel Estrada y Cía. S.A. c. Secretaría de Energía y Puertos”, Fallos: 328:651.

11. Nota del autor: cuyo ordenamiento administrativo de consumo (ley 757) incluye la obligación de la autoridad de aplicación de informar al consumidor la posibilidad de peticionar la aplicación de este instituto, regulando las formalidades de su inclusión en la denuncia, y hasta facultades procedimentales del consumidor que haga uso de ella, que jurisprudencialmente fueron evolucionando hasta la apelación de la decisión que lo deniegue o lo otorgue en menor medida que la solicitada 
Dichos tribunales arbitrales tendrán asiento en la Ciudad Autónoma de Buenos Aires y en todas las ciudades capitales de provincia. Regirá el procedimiento del lugar en que actúa el tribunal arbitral”.

El sistema tiene como finalidad atender y resolver con carácter vinculante los reclamos debido a los derechos y obligaciones emergentes de la Ley de Defensa y Protección del Consumidor N. o 24.240, mediante procedimientos más rápidos, sencillos y económicos que los del sistema judicial, con las características que señalaremos.

Puede someterse a los Tribunales Arbitrales de Consumo todo asunto donde estén en juego derechos emanados de la Ley de Defensa del Consumidor, así como de toda otra norma o asunto del que se deriven cuestiones relacionadas a los derechos de consumidores o usuarios, y desde luego quedan comprendidos los servicios públicos. Otro sector de la doctrina define quizá más estrictamente a la competencia del Tribunal Arbitral, señalando que sólo son susceptibles de ser sometidas a su tratamiento las cuestiones que se encuentren comprendidas en la competencia de las autoridades de aplicación de la ley $24.240^{12}$.

Están expresamente excluidas del sistema las cuestiones que no pueden someterse al proceso arbitral: aquellas sobre las que haya recaído resolución judicial firme y definitiva, (con autoridad de cosa juzgada), las que puedan dar origen a juicios ejecutivos, las que con arreglo a las leyes no puedan ser sometidas a juicio arbitral (por no poder ser materia de transacción o estar en juego el orden público); las materias inseparablemente unidas a otras sobre las que las partes no tengan poder de disposición y/o que no puedan ser sometidas a juicio arbitral; aquellas que se deriven daños físicos, psíquicos y/o muerte del consumidor; aquellas en las que exista la presunción de la comisión de un delito (en ese caso corresponderá la remisión a la justicia penal), y las cuestiones que por el monto reclamado queden exceptuadas por la reglamentación (no se ha dictado ninguna exclusión en razón del monto, pero apuntamos que la existencia de una limitación a la competencia arbitral por montos pequeños desvirtuaría la finalidad del sistema).

Esencialmente, el Sistema tiene las siguientes notas características salientes: voluntariedad, gratuidad, oficiosidad, celeridad, (consecuencia de anterior, el trámite no depende del impulso de las partes ni está sujeto a demoras por falta de éste ${ }^{13}$ ), neutralidad, sencillez, ausencia de patrocinio letrado obligatorio, posibilidad para los consumidores de ser representados por una asociación de consumidores y los proveedores por una asociación empresarial, aceptación de la obligatoriedad del laudo.

El uso de un logotipo que permite el sistema a los proveedores adheridos, en los países donde funciona plenamente y es conocido por el público consumidor, constituye para los proveedores una herramienta de marketing sano, a través de la cual comunican a los que con ellos se relacionen en ma-

12. Horacio Luis Bersten. Derecho Procesal del Consumidor, (Buenos Aires, La Ley, 2003), 114

13. Horacio Luis Bersten, Derecho Procesal del Consumidor, op. cit., 108. 
teria de consumo que en caso de controversias se encuentran adheridos a un sistema rápido y sencillo en materia de solución de conflictos.

No obstante, la idea del arbitraje ha estado lejos de arraigar en el consumidor argentino, el cual en su generalidad no conoce la existencia del sistema, o bien, se encuentra lejos de la sede del mismo, teniendo en cuenta que pocas provincias han organizado su sistema arbitral ${ }^{14}$. Por esa razón, y la poca difusión que ha tenido tanto a nivel estatal como en los propios proveedores (no tanto en los consumidores y en sus organizaciones), si bien las presentaciones y los casos sometidos a laudo han crecido significativamente, no son vislumbrados como una herramienta ya impuesta o instalada, que los consumidores tengan presente y por eso es necesario que sea conocida y difundida.

La Resolución 65/2018 de la Secretaria de Comercio de la Nación introdujo el mundo informático al sistema de arbitraje, a los efectos de su aggiornamiento, previendo el domicilio electrónico, la adhesión de los proveedores por ese medio al sistema, y las notificaciones del procedimiento.

El laudo arbitral produce idénticos efectos a la cosa juzgada, para ambas partes, las reclamaciones de los consumidores y usuarios, en relación con los derechos y obligaciones emergentes de la Ley No 24.240, y de toda ley, decreto y cualquier otra reglamentación que consagre derechos y obligaciones para los consumidores o usuarios en las relaciones de consumo.

Existen Árbitros Institucionales, que son seleccionados entre los abogados que se postulen para ello y que desempeñen sus tareas en el ámbito de la Secretaria de Comercio y Árbitros Sectoriales propuestos por las Asociaciones de Consumidores y las Asociaciones Empresariales, determinándose los requisitos que deben cumplir para su designación.

En todo conflicto que se plantee ante el sistema, cuyo monto sea igual o superior al $50 \%$ del Salario Mínimo Vital y Móvil, fijado por el Consejo Nacional de Empleo, la Productividad y el Salario Mínimo, Vital y Móvil, el Tribunal será colegiado, formado por un árbitro institucional y un árbitro por cada sector (consumidores y empresas).

Las partes deben suscribir el correspondiente acuerdo arbitral en forma presencial, o por vía electrónica, aceptando las reglas del procedimiento y que las costas se fijaran siempre en el orden causado, dato que debe ser siempre tenido en cuenta por el consumidor y el abogado que lo asesore.

El arbitraje de amigables componedores sucintamente tramita de la siguiente manera: si la cuestión amerita tribunal colegiado, conformado con los árbitros sectoriales en los breves plazos previstos en la

14. Nota del autor: la Provincia de Buenos Aires creó, por Decreto 1667/99 del 10 de junio de 1999, el Sistema Provincial de Arbitraje de Consumo, Mendoza lo hizo adhiriendo al Sistema Nacional por Decreto Provincial 1012/98. La Ciudad Autónoma de Buenos Aires, mediante ley n 2.963, y ejerciendo las facultades que le atribuye el artículo 80 de su Constitución, en materia "de defensa del usuario y consumidor" crea, en su artículo 1: "el Sistema Arbitral de Consumo de la Ciudad Autónoma de Buenos Aires" aunque hasta la fecha en que esto se escribe no tenga funcionamiento concreto. 
normativa, el proveedor cuenta con diez días para contestar el reclamo y ofrecer prueba. Contestada la reclamación o vencido el plazo para hacerlo, se señala audiencia en un plazo máximo de diez días hábiles. En ella se intentará una conciliación y de no ser posible, se dicta el laudo en un plazo máximo de quince días después de finalizada la audiencia y de ser el tribunal unipersonal, dentro los cinco días.

El arbitraje de derecho que abarca los conflictos cuyo monto sea igual o superior a dos (2) Salarios Mínimos, Vitales y Móviles, fijado por el Consejo Nacional de Empleo, la Productividad y el Salario Mínimo, Vital y Móvil, es una opción para las partes, y se concreta mediante tribunal colegiado. La causa se abre a prueba por veinte días, y se producen antes de la fecha de audiencia, que se determina en el auto de apertura. El laudo se dicta en un plazo máximo de quince días desde la realización de la audiencia.

El laudo se decide por mayoría de votos, pudiéndose plasmar por escrito o en forma electrónica y debe ser fundado. Su incumplimiento da derecho a promover su ejecución en sede judicial, siendo competente el fuero en razón de la materia con jurisdicción en el lugar de asiento del Tribunal.

\section{EL ROL DE LAS ASOCIACIONES DE CONSUMIDORES}

Las asociaciones de consumidores constituidas como tales están reglamentadas en los artículos 55 a 58 de la ley 24240. Su intervención se halla delimitada por su competencia material conforme a los fines estatutarios, y al ámbito geográfico en que se encuentran inscriptas. Para que se materialice y sea efectiva, tanto el estado como el sector social deben difundir ampliamente esta posibilidad, y que la ciudadanía conozca que se puede solicitar asesoramiento y representación en estas entidades.

El artículo 55 de la ley de defensa del consumidor al tratar a las asociaciones de consumidores refiere a personas jurídicas reconocidas por la autoridad de aplicación, y el artículo 56 de la misma norma, como se verá, refiere a organizaciones que tengan por la finalidad la defensa, información y educación del consumidor, permitiendo inferir que las asociaciones de consumidores en tanto personas jurídicas privadas, pueden revestir la forma de Asociación civil, simple asociación, cooperativa, o fundación ${ }^{15}$.

Con relación al procedimiento administrativo y al sistema arbitral, estas organizaciones pueden obrar en representación de un consumidor particular que así lo requiera como en defensa de intereses de incidencia colectiva representando a los afectados dentro del ámbito en que tengan autorización para funcionar. Su accionar no aplica solamente para la defensa de sus asociados afectados, sino para todo el universo de consumidores y usuarios vulnerados por prácticas de los proveedores de bienes y servicios en el ámbito local o nacional, según su reconocimiento y consecuente localización de su autorización para funcionar.

15. Véase María Eugenia D Archivio, Comentario al art. 55 y siguientes de la ley nacional 24240, Ley de defensa del consumidor. Comentada. Anotada. Concordada, Carlos Eduardo Tambussi (dir), (Buenos Aires: Hammurabi, 2017), 245 y sgtes. 
Las Asociaciones son un instrumento de concreción de las garantías constitucionales y de la ley de defensa del consumidor, al crear lazos asociativos entre los consumidores y al ser consideradas actores procesales de estos derechos, que de forma individual tendrían difícil defensa, o se consideraría antieconómico el reclamo, siendo sólo factibles de ser llevados adelante en una acción colectiva. Constituyen grupos organizados que actúan con criterio independiente, apolítico y sin fines de lucro. Su actividad está reconocida por ley y encaminada a educar, informar y orientar, proteger y defender los intereses del consumidor o usuario. Su función se resume en velar por el cumplimiento de las disposiciones legales, normas y reglamentos que protegen al consumidor, y colaborar en la formulación de propuestas técnicas, legislativas y de organización, tanto del servicio en sí mismo como de la actividad de control. Que tengan consideración legal y constitucional importa una política de Estado para su fortalecimiento como formas de democracia social, y de alguna manera su sostenimiento, por cuanto éstas pueden constituir una alternativa de poder en cuanto a los fines que les conciernen, como contrapeso al desamparo de la relación individual del consumidor frente al poderoso productor, a veces único proveedor del bien que el más débil forzosamente debe obtener para la satisfacción de sus necesidades de todo tipo, desde las más elementales, hasta las suntuarias. La ley determina como condiciones especiales que las asociaciones no podrán participar en actividades políticas partidarias; deberán ser independientes de toda forma actividad profesional, comercial y productiva; no pueden percibir donaciones, aportes o contribuciones de empresas comerciales, industriales o proveedoras de servicios, privadas o estatales, nacionales o extranjeras y sus publicaciones no pueden contener avisos publicitarios.

\section{EL DEFENSOR DEL PUEBLO}

El papel de este funcionario es fundamental de esta figura para la tutela de los derechos del consumidor y de los derechos humanos en general, no solamente en su rol como legitimado activo para acceder a la justicia en defensa de estos valores, sino como órgano de control, receptor de las quejas de los ciudadanos, y activo difusor y divulgador de los derechos ciudadanos.

Conforme el artículo 86 de la Constitución Nacional “...su misión es la defensa y protección de los derechos humanos y demás derechos, garantías e intereses tutelados en esta Constitución y las leyes, ante hechos, actos u omisiones de la Administración; y el control del ejercicio de las funciones administrativas públicas".

La institución fue regulada por la ley 24.284, anterior a la reforma de 1994, que determina las funciones del Defensor del Pueblo de la Nación. Su artículo 1 establece que "El objetivo fundamental de esta institución es el de proteger los derechos e intereses de los individuos y la comunidad frente a los actos, hechos y omisiones de la Administración Pública Nacional, que se mencionan en el artículo 14".

El artículo 14 aludido, a su vez, faculta al Defensor del Pueblo a "iniciar y proseguir de oficio o a petición del interesado cualquier investigación conducente al esclarecimiento de los actos hechos u omisiones de la Administración Pública Nacional y sus agentes, que impliquen el ejercicio ilegítimo, 
defectuoso, irregular, abusivo, arbitrario, discriminatorio, negligente, gravemente inconveniente o inoportuno de sus funciones, incluyendo aquello capaces de afectarlos intereses difusos o colectivos"

El Defensor está calificado como órgano independiente instituido en el ámbito del Congreso de la Nación que actuará con plena autonomía funcional, sin recibir instrucciones de ninguna autoridad, aspecto que debe verse en relación directa con las atribuciones otorgadas al mismo por la propia Carta Magna.

En nuestro país, existe una Defensoría del Pueblo nacional y múltiples defensorías provinciales, municipales y la Defensoría de la Ciudad Autónoma de Buenos Aires. Cada una de estas instituciones ha sido regulada por las normas locales que, no obstante reunir la mayor parte de las características mencionadas supra, poseen peculiaridades y rasgos distintivos.

Por ejemplo, en la Ciudad Autónoma de Buenos Aires, se encuentra previsto en el artículo 137 de su Constitución, y su misión es la defensa, protección y promoción de los derechos humanos y demás derechos fundamentales frente a los actos, hechos u omisiones que ejecuten, principalmente, la Administración y los prestadores de servicios públicos, aunque en ocasiones por su accionar también alcanza a los sectores privados. También tiene facultades para desarrollar investigaciones (por denuncia o de oficio) "ya sea para detectar y, en su caso, subsanar disfuncionalidades administrativas, o bien para cooperar con la Autoridad de Aplicación en la plena y efectiva vigencia de estos derechos" ${ }^{16}$. A su vez, ha tomado intervención directa en conflictos de consumo, mediante métodos alternativos.

Los conflictos entre particulares quedan, como vimos, excluidos del ámbito de actuación de la Institución; sin embargo, en los casos en que ingresa en la Defensoría una presentación de estas características, si existe un organismo público con competencia para intervenir, se puede brindar a la queja el trámite de derivación, poniendo la presentación en conocimiento del organismo que corresponda.

\section{CONCLUSIONES}

Los sistemas extrajudiciales de reclamos del consumidor son un camino válido para el ejercicio responsable de estos derechos.

- Estimulan la responsabilidad social empresaria si se utilizan las vías para quejas que ofrecen las empresas.

- Hacen al ejercicio de la civilidad, poniendo en conocimiento de la autoridad de aplicación infracciones a la ley.

- Jerarquizan al sector social, otorgando un rol activo a las organizaciones de consumidores.

16. Norberto Carlos Darcy, "Defensa del consumidor en la Defensoría del Pueblo", La Ley On Line. 
- Ofrecen instancias conciliatorias en las que puede rápidamente arribarse a una solución para el problema, dependiendo de la voluntad de acuerdo de las partes.

- Amplían las bocas de atención de planteos, derivan asuntos a los organismos específicos en ventanillas de atención general, introducen la presentación electrónica de denuncias y la realización de trámites en forma virtual.

- No son excluyentes, salvo el arbitraje, de la vía judicial en caso de no lograrse respuesta satisfactoria

\section{REFERENCIAS}

- Amaya, Jorge Alejandro. Mecanismos Constitucionales de Protección al Consumidor. Buenos Aires: Ed. La Ley, 2004.

- Balbín, Carlos. Tratado de Derecho Administrativo. Tomo 2, Buenos Aires: Ed. La Ley, Bs. As, 2015.

- Bersten, Horacio Luis. Derecho Procesal del consumidor. Buenos Aires: Ed. La Ley, 2004.

- Calderón Maximiliano Rafael, Cornet Manuel, Tinti Guillermo, Márquez José Fernando. “Proceso judicial de Consumo. Análisis de los arts. 52 y 53 de La Ley 24.240". Revista La Ley, Córdoba Ed. La Ley, (junio 2009): 459.

- D Archivio María Eugenia. "Comentario al art. 55 y siguientes de la ley nacional 24240". Ley de defensa del consumidor. Comentada. Anotada. Concordada. Carlos Eduardo Tambussi (dir), Buenos Aires, Hammurabi, (2017): 245 y sgtes.

- Darcy, Norberto Carlos. "Defensa del consumidor en la Defensoría del Pueblo”. La Ley, On Line.

- $\quad$ Farina, Juan. Defensa del Consumidor y del Usuario. Buenos Aires: Ed. Astrea, 2000.

- Tambussi Carlos. "Juicios y Procesos de Consumidores y Usuarios". Colección Procesos Constitucionales $N^{o}$ 7. Pablo Luis Manili (director). Buenos Aires: Ed. Hammurabi (2014).

- Tambussi, Carlos. "La teoría de las cargas dinámicas de la prueba en los procesos de consumo". Erreius, Revista Temas de derecho comercial, empresarial y del consumidor, Año 1, diciembre (2015): 43-49.

- Vanossi, Jorge Reynaldo. "La aplicación constitucional del Análisis Económico del Derecho: nada menos y nada más que un enfoque?" En Anales de la Academia Nacional de Ciencias Morales y Políticas. Tomo XXXV, (2008) parte I. 